\title{
Desigualdad en la dotación de capital como determinante de la segmentación del mercado de crédito: el caso de los productores de plátano en Nicaragua
}

\section{Alder Miguel Contreras Hernández*}

\section{Recibido: octubre de 2014 / Aceptado: noviembre de 2014}

El crédito constituye una de las herramientas fundamentales de fomento al crecimiento y el desarrollo económico, por lo que el desempeño de las instituciones financieras que se encargan de su distribución impacta directamente en tales procesos. No obstante, es posible que los niveles de desigualdad de ingreso y de tenencia de capital influyan también en el modus operandi de dichas instituciones crediticias, formándose así un efecto de doble causalidad entre el desempeño de los mercados de crédito y los procesos de crecimiento y desarrollo. En este artículo se analiza precisamente el impacto que tienen los niveles de desigualdad de ingresos y de tenencia de capital sobre la estructura del mercado de crédito, utilizando como caso de estudio el de los productores de plátano nicaragüenses. Para ello se crea una tipología de productores basada tanto en la dotación de capital tierra y capital trabajo que poseen, como en la tecnología productiva y de comercialización que implementan en sus explotaciones agropecuarias. Luego se explora si existe un vínculo entre dichas características y el tipo de institución crediticia a la que tienen acceso. Se argumenta que las desigualdades entre productores provocan una segmentación del mercado de crédito en la que los pequeños y medianos productores acceden a aquellas fuentes con mayores costos de financiamiento y menor capacidad de recursos. Por ello, el desarrollo de alternativas crediticias y el otorgamiento de servicios complementarios al financiamiento para estos productores es clave para generar un proceso de crecimiento y desarrollo más inclusivo.

Palabras clave: productores / instituciones crediticias / segmentación / mercado de crédito 


\section{Introducción}

Cualquier proceso de crecimiento y desarrollo económico, sobre todo en países en vías de desarrollo y predominantemente agrícolas como Nicaragua, debe implicar una transformación estructural del sector agrícola que permita a las personas obtener suficiente rentabilidad de sus actividades en el campo como para evitar su traslado a los centros urbanos, y así respaldar y mantener un equilibrio eficiente con los demás sectores de la economía (Ray, 2003). Según Vieira (2013), dicha transformación solo es posible si se establecen simultaneamente políticas de corto plazo -como ayuda a grupos vulnerables y transferencia de recursos monetarios y productivos- y políticas de largo plazo -como el mejoramiento de los servicios básicos y el sistema educativo, y la dotación de infraestructura de mercado. En este sentido, el crédito desempeña un rol fundamental al permitir la creación y el fortalecimiento especialmente de las unidades productivas más pequeñas, al ser el mecanismo mediante el cual éstas logran adquirir los recursos suficientes para crear, consolidar y/o transformar sus sistemas productivos (Padilla-Pérez \& Fenton, 2013).

En Nicaragua el sector agrícola presenta serios problemas estructurales que resultan en bajos niveles de productividad y fuertes desigualdades de ingreso y de dotación de capital entre productores. A pesar de esto, existen algunas actividades agrícolas que han presentado marcadas dinámicas de crecimiento, como es el caso del cultivo del plátano. Por lo tanto, el estudio de las dinámicas productivas y organizativas de los productores dedicados a esta actividad es clave para ayudar a que dicho crecimiento sea motor de arranque de un proceso de desarrollo que incorpore y mejore el bienestar de los grupos más vulnerables. En este sentido, el desarrollo de alternativas crediticias para los pequeños y medianos productores es clave para la generación de tal proceso de desarrollo. Según Bastiaensen y Marchetti (2011), para estos productores el recibimiento de crédito y servicios complementarios de seguimiento y fomento de capacidades productivas y organizativas constituye un factor indispensable para desencadenar mejoras significativas en sus condiciones de vida.

No obstante, Asorena (2007) sostiene que el mercado de crédito nicaragüense posee serias deficiencias en cuanto a su estructura y funcionamiento que limitan su impacto en el desarrollo de los sectores productivos. Al respecto, Levine (1997) sostiene que las deficiencias del mercado crediticio afectan negativamente el desempeño productivo y el desarrollo de los sectores a los que atiende. Sin embargo, Castro y Jayme (2008) argumentan que es probable que las características de los agentes demandantes de crédito influyan también en el desempeño de las instituciones credicias involucradas. Sobre esto, Figueroa (2011) sostiene que los altos niveles de desigualdad de ingresos y de capital, frecuentes en economías en desarrollo, propician una estructura segmentada del mercado de crédito según la naturaleza de las instituciones que lo conforman: formal bancario, formal no bancario e informal. En estas condiciones solo aquellos productores con mayor riqueza acceden a las fuentes de crédito con menores costos de financiamiento y mayor capacidad de otorgamiento de recursos, por lo que el mercado de crédito estaría impulsando la desigualdad económica entre productores agrícolas en vez de 
contrarrestarla.

Así entonces, el objetivo de la investigación realizada fue determinar si la estructura del mercado de crédito agrícola propicia la desigualdad económica y el retraso productivo en el caso específico de los productores de plátano en Nicaragua. Para ello se elaboró una tipología de productores utilizando conjuntamente un Análisis de Componentes Principales (PCA por sus siglas en inglés) y un Análisis de Clusters (CA por sus siglas en inglés). La información fue recopilada del Censo Nacional Agropecuario (CENAGRO) aplicado en Nicaragua en el año 2011, tomando elementos relacionados a la dotación de tierra y mano de obra, las características productivas y métodos de comercialización. La muestra fue de 597 productores de plátano. Los resultados de la tipología fueron contrastados con una clasificación de las instituciones crediticias según su naturaleza (formal bancaria, formal no bancaria o informal) a las que los productores reportaron haber tenido acceso. De esa manera se trató de determinar si existe algún vínculo entre la dotación de recursos de los productores del sector platanero y el tipo de institución a la cual tienen acceso.

En la segunda parte del artículo se desarrolla un modelo que explica cómo la desigualdad de ingresos y de dotación de capital provoca una estructura segmentada del mercado de crédito, que a su vez impide que las pequeñas y medianas unidades productivas tengan acceso a las fuentes de crédito con mayor capacidad de otorgamiento de recursos y menos costos financieros. En la tercera parte se brinda un panorama general de la situación del sector agrícola y la correspondiente evolución del sector platanero dentro del mismo, así como las principales características del sistema crediticio nicaragüense. En la cuarta parte se discute la metodología utilizada para luego, en la quinta parte, realizar la discusión de los resultados obtenidos. Por último, en la sexta y séptima parte se reportan las principales conclusiones y recomendaciones derivadas de la investigación.

\section{Características y estructura de los mercados crediticios}

\subsection{El mercado de crédito bancario}

La naturaleza de las transacciones que se realizan en el mercado de crédito bancario es la de intercambiar determinada suma de dinero con la promesa de devolver, en el futuro, dicha suma más unos intereses también monetarios (McCallum, 1989). La base fundamental de estas transacciones radica en el hecho de que ciertos agentes de la economía prefieren trasladar consumo presente al futuro mediante el ahorro, mientras que otros desean consumir más allá de su restricción presupuestaria, para lo cual deben solicitar préstamos. En este escenario los bancos surgen como intermediarios financieros encargados de solucionar el problema de coincidencia de intereses al reunir indirectamente a oferentes y demandantes de recursos monetarios (Walsh, 2010). Basado en esta función de los bancos, Figueroa (2011) identifica tres regularidades relacionadas a su comportamiento empírico: 1) exigen garantías por los créditos otorgados, 2) operan en condiciones de exceso de demanda, y 3) coexisten con otros tipos de instituciones crediticias. Éstas regularidades resultan fundamentales para comprender el porqué de la segmentación del mercado de 
crédito en presencia de desigualdad de ingresos y de capital.

En esta sección del artículo se darrolla el modelo de equilibrio parcial del mercado de crédito bancario propuesto por Figueroa (2011) con ligeras modificaciones. Éste permite explicar cómo la presencia de garanterías, el exceso de demanda y la existencia de otras formas de crédito, junto a la desigualdad de ingresos y de tenenecia de capital, provocan una segmentación del mercado de crédito. El modelo predice una división del mercado crediticio basada en la naturaleza de las instituciones financieras que lo conforman. El primer sector se compone de los usuarios de crédito con ingresos altos y los bancos, el segundo los usuarios de ingresos medios y las entidades crediticias no bancarias, y el tercero los usuarios de ingresos bajos y las fuentes de crédito informales (ver Ilustración 1.).

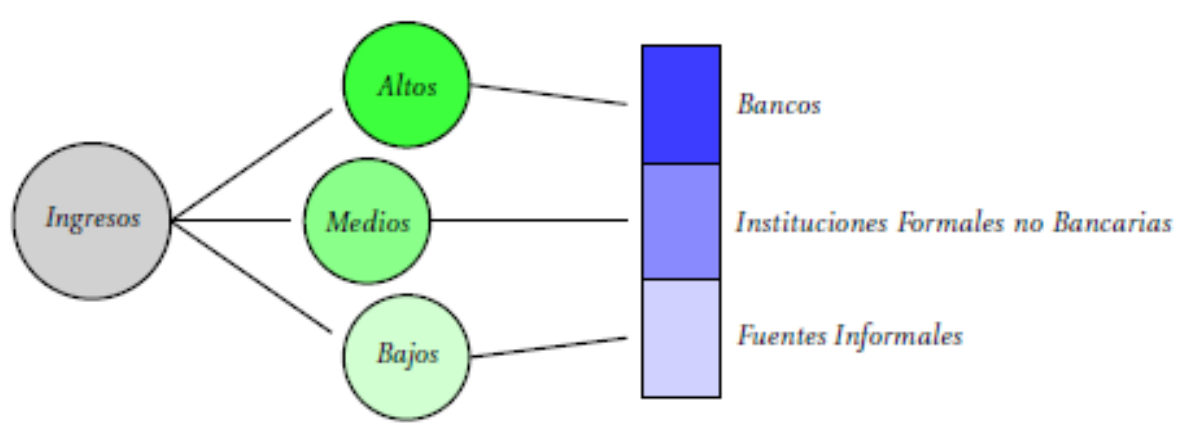

Ilustración 1. Segmentación del mercado de crédito debido a la desigualdad de ingresos

Fuente: Elaboración propia.

Para explicar el funcionamiento del sector bancario y cómo este proceso origina una segmentación del mercado crediticio, el modelo supone que nos encontramos en una sociedad altamente desigual en cuanto al nivel de ingresos y la tenencia de bienes de capital. En este escenario, los bancos operan con altos niveles de incertidumbre, costos de transacción e información asimétrica, lo que a su vez provoca que éstos exijan garantías como mecanismos de protección ante la posibilidad de incumplimiento del pago de los créditos otorgados. Además, se supone que la actividad bancaria presenta economías de escala en relación a los costos de otorgamiento de dichos préstamos. Es más llamativo para los bancos otorgar un único gran crédito que muchos pequeños.

Para efectos de modelización se supone que el sector bancario está integrado por un mercado de crédito bancario -formado a su vez por los bancos que ofrecen el crédito y las empresas que lo demandan- y por un mercado de depósitos -formado por los hogares, quienes determinan la oferta de depósitos que a su vez es captada por los bancos (ver Ilustración 2). Así, el rol fundamental de los bancos es canalizar los recursos monetarios de los hogares hacia las empresas. Será el comportamiento individual y el vínculo entre bancos, empresas y hogares, el objeto de estudio de las siguientes subsecciones. 


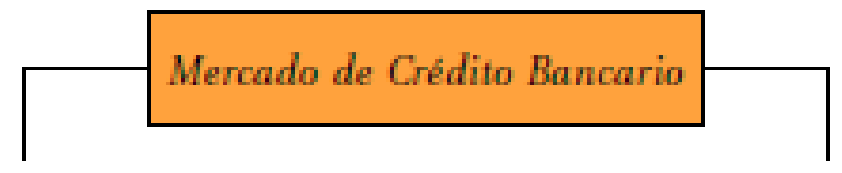

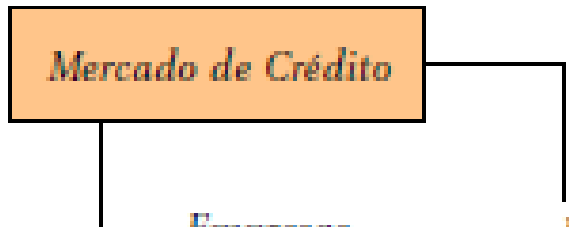

Empresas

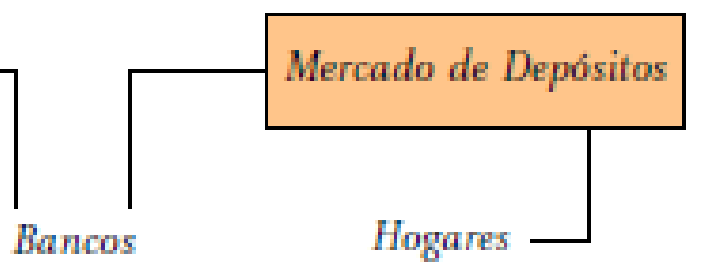

Ilustración 2. Estructura del mercado de crédito bancario Fuente: Elaboración propia.

\subsubsection{Los bancos y la oferta de crédito}

El tipo de actividad que ejercen los bancos conlleva a la creación de mecanismos para garantizar que, en caso de incumplimiento, la entidad bancaria pueda recuperar el dinero invertido. En este sentido, las garantías juegan un rol importante, ya que crean incentivos para que la entidad deudora asuma el pago de su deuda (Figueroa, 2011). Bajo el supuesto de que el costo de recuperar las garantías es el mismo para todas las empresas demandantes de crédito, todas son homogéneas desde el punto de vista de una institución bancaria. Por ello, los bancos pueden actuar bajo el modelo estándar de oferta y demanda con el fin de maximizar sus beneficios. Esto significa que los bancos pueden ofrecer cualquier volumen de crédito dada la tasa de interés del mercado de crédito bancario, y pueden captar cualquier volumen de depósitos dada la tasa de interés del mercado de depósitos.

Dados los supuestos anteriores, un banco tendrá el siguiente comportamiento a corto plazo:

$$
\begin{aligned}
\text { Máx } P_{k} & =r S_{r k}-\tilde{r} \widetilde{D}_{r k}-C_{k}-F C_{k} \\
\text { Sujeto a } C_{k} & =\widetilde{D}_{r k} \\
S_{r k} & =\sum_{j=1}^{n} s_{k j}, \text { tal que } s_{k j} \geq s^{*} \forall j=1,2, \ldots, n \\
S_{r k} & ={ }^{n}
\end{aligned}
$$

La expresión (2.1) es la función de beneficios relacionada a los beneficios nominales, $P$, del banco, donde $r$ es la tasa de interés de los préstamos, $S_{r}$ es el volumen de crédito, $\tilde{r}$ es la tasa de interés de los depósitos, $\widetilde{D}_{r}$ es el volumen de depósitos, $C$ es una función de los costos variables por intermediación y $F C$ son los costos fijos por intermediación. La expresión (2.2), que es la función de costos variables, establece una relación entre estos costos y el volumen de crédito, cuya naturaleza implica que el costo marginal por otorgar un préstamo es creciente en relación a dicho volumen con presencia de economías de escala. Es decir, que el incremento de los costos marginales se aminoriza conforme aumenta el volumen 
de crédito otorgado. Además, se asumen que el monto de crédito otorgado por individuos, $s_{k}$, debe ser superior al umbral $s^{*}$, lo que significa que una entidad $j$ solo podrá obtener un préstamo si el monto del mismo es superior a $s^{*}$.

El problema del banco $k$ consiste en determinar el volumen de crédito otorgado que maximice sus beneficios, cuya solución da como resultado una función de asignación de crédito de la forma:

$$
\begin{aligned}
S_{r k} & =F^{k}(r, \tilde{r}) ; \quad F_{1}^{k}>0, F_{2}^{k}<0 \\
\widetilde{D}_{r k} & =S_{r k} \\
r & >\tilde{r}
\end{aligned}
$$

Las expresiones (2.3) y (2.4) establecen, por un parte, que un aumento de la tasa de interés de los préstamos provoca un incremento del volumen de crédito otorgado, mientras que un aumento de la tasa de interés de los depósitos lo disminuye. Por otra parte, el aumento del volumen de crédito provoca un incremento en el volumen de depósitos que los bancos deben captar para satisfacer dichos préstamos. Además, la solución es tal que la tasa de interés de los créditos es siempre superior a la de los depósitos.

El comportamiento global de los bancos se obtiene agregando las ecuaciones (2.3) y (2.4) de los $p$ bancos del sector:

$$
\begin{aligned}
& \sum_{\substack{k=1 \\
p}}^{p} S_{r k} \equiv S_{r}=F(r, \tilde{r}) ; \quad F_{1}>0, F_{2}<0 \\
& \sum_{k=1}^{p} \widetilde{D}_{r k} \equiv \widetilde{D}_{r}=S_{r}
\end{aligned}
$$

La expresión (2.5) es la función de oferta de crédito y la expresión (2.6) es la función de demanda de depósitos.

\subsubsection{Los hogares y la oferta de depósitos}

Se supone que los hogares poseen una demanda de dinero basada en necesidades operativas y de precaución, y que éstos solo pueden elegir entre dos tipos de activos financieros: dinero en efectivo y depósitos. Por un lado, el dinero es muy líquido, pero genera intereses, por otro, los depósitos generan intereses, pero son poco líquidos. Bajo este contexto, el hogar representativo se enfrenta al problema de establecer una cartera óptima entre dinero en efectivo y depósitos, cuya estructura dependerá de la tasa de interés de los depósitos, $\tilde{r}$, y el ingreso del hogar, $Y$.

Dados estos supuestos, podemos representar el comportamiento de un hogar $h$ como:

$$
\tilde{S}_{r h}=G^{h}(\tilde{r}, Y) ; \quad G_{1}^{h}>0, G_{2}^{h}>0
$$


Según la ecuación (2.7), cada hogar determina su demanda de dinero y, por ende, su volumen de depósitos, $\tilde{S}_{r}$, en función del tipo de interés de los depósitos, $\tilde{r}$, y su renta, $Y$. Un aumento en la tasa de interés de los depósitos o un aumento en la renta provocará un incremento en los depósitos.

El comportamiento global de los hogares se obtiene agregando la ecuación (2.7) de los $q$ hogares en la economía:

$$
\sum_{h=1}^{q} \tilde{S}_{r h} \equiv \tilde{S}_{r}=G(\tilde{r}, Y) ; \quad G_{1}>0, G_{2}>0
$$

La expresión (2.8) es la función de oferta de depósitos.

\subsubsection{Las empresas y la demanda de crédito}

Como se expresó anteriormente, la demanda de crédito bancario proviene exclusivamente de las empresas. En este sentido, se consideran dos tipos de créditos bancarios: 1) para financiamiento de capital de trabajo -corto plazo- y 2) para financiar la acumulación de capital -largo plazo. Sin embargo, serán los mecanismos de oferta y demanda del primer tipo de crédito los que se analizarán en el presente artículo.

Suponemos que las empresas están dotadas de una cantidad $K$ de bienes de capital y producen un solo bien $B$ que venden a un precio $P_{b}$. Éstas, además, utilizan una cantidad $D_{Z}$ de un único tipo de mano de obra, cuyo salario es $P_{Z}$, para producir determinada cantidad del bien $B$. Por otra parte, se asume que las empresas utilizan un capital de trabajo en forma de un fondo financiero que obtienen a partir de préstamos bancarios. Esto último se puede representar mediante $D_{r}=v P_{b} Q_{b}$, donde $D_{r}$ es el volumen de crédito demandado y $v$ es el coeficiente técnico del capital de trabajo por unidad del valor de producción, $P_{b} Q_{b}$.

Dado los supuestos anteriores, una empresa $t$ tendrá el siguiente comportamiento a corto plazo:

$$
\begin{aligned}
\text { Máx } P_{t} & =P_{b} Q_{b t}-P_{z} D_{z t}-r D_{r t} \\
\text { Sujeto a } Q_{b t} & =G^{t}\left(D_{z t}\right) ; \quad g_{1}^{t}>0 \\
Q_{b t} & =\frac{D_{r t}}{v_{t} P_{b}}
\end{aligned}
$$

La expresión (2.9) es la función de beneficios relacionados a los beneficios nominales, $P$, de la empresa, que equivale al valor neto de producción, $P_{b} Q_{b}$, menos el costo de la mano de obra, $P_{Z} Q_{z t}$, y el costo del préstamo a corto plazo, $r D_{r t}$.

A corto plazo el problema de la empresa $t$ consiste en determinar la cantidad de mano de obra que maximice sus beneficios, cuya solución da como resultado una función de demanda de crédito de la forma: 


$$
D_{r t}=J^{t}\left(r, P_{b}, K_{t}, P_{z}\right) ; \quad j_{1}^{t}<0, j_{2}^{t}>0, j_{3}^{t}>0, j_{4}^{t}<0
$$

La expresión (2.11) establece, por un lado, que un aumento de la tasa de interés del crédito o del precio unitario de la mano de obra disminuye el volumen de crédito demandado. Por otro, un aumento en el precio del bien que produce la empresa o en la cantidad de bienes de capital que ésta posee incrementa el volumen de crédito demandado.

El comportamiento global de las empresas puede obtenerse agrupando la ecuación (2.11) de las empresas en la economía:

$$
\begin{aligned}
\sum_{t=1}^{m} D_{r t} \equiv D_{r}^{*} & =J\left(r, P_{b}, K, P_{z}\right) ; \quad J_{1}<0, J_{2}>0, J_{3}>0, J_{4}<0 \\
K & =\sum_{t=1}^{m} K_{t}, \text { tal que } K_{t} \geq s^{*} \forall t=1,2, \ldots, m \text { y } m<n
\end{aligned}
$$

La expresión (2.12) implica que el volumen de crédito demandado por las empresas solo incluye la demanda de crédito de aquellas empresas cuyo monto solicitado es superior a $s^{*}$, que es igual al monto mínimo que los bancos otorgan por préstamo. Esto significa que la demanda global de crédito, $D_{r}$, es inferior a la demanda efectiva de crédito, $D_{r}^{*}$; por lo que todas las empresas pequeñas comprendidas entre $n-m$ quedarán excluidas del mercado de crédito bancario.

\subsubsection{El equilibrio del mercado de crédito bancario}

La condición de equilibrio del mercado de crédito bancario puede expresarse como la igualdad entre la oferta y la demanda de crédito, y la oferta y la demanda de depósitos, por lo que:

Mercado de crédito $F(r, \tilde{r})=J\left(r, P_{b}, K, P_{z}\right)$
Mercado de depósito $G(\tilde{r}, Y)=S_{r}$

El sistema formado por las ecuaciones (2.13) y (2.14) permite encontrar los valores de la tasa de interés de los préstamos, $r$, la tasa de interés de los depósitos, $\tilde{r}$, el volumen de crédito ofertado, $\tilde{S}_{r}$, y el volumen de crédito demandado, $\widetilde{D}_{r}$, que equilibran el mercado de crédito bancario (ver Ilustración 3). Por un lado, en el punto en el que las curvas de oferta de crédito, $S$, y demanda de crédito, $D^{*}$, se interceptan, se determina el volumen de crédito recibido por las empresas, $M^{\circ}$, y la tasa de interés que los bancos cobran por otorgar dichos créditos, $r^{\circ}$. Por otro lado, en el punto en el que las curvas de oferta de depósitos, $\tilde{S}$, y demanda de depósitos, $\widetilde{D}$, se interceptan, se determina el volumen de depósitos de los hogares, $\widetilde{M}^{\circ}$, y la tasa de interés que los bancos pagan por captar dichos depósitos, $\tilde{r}^{\circ}$. 


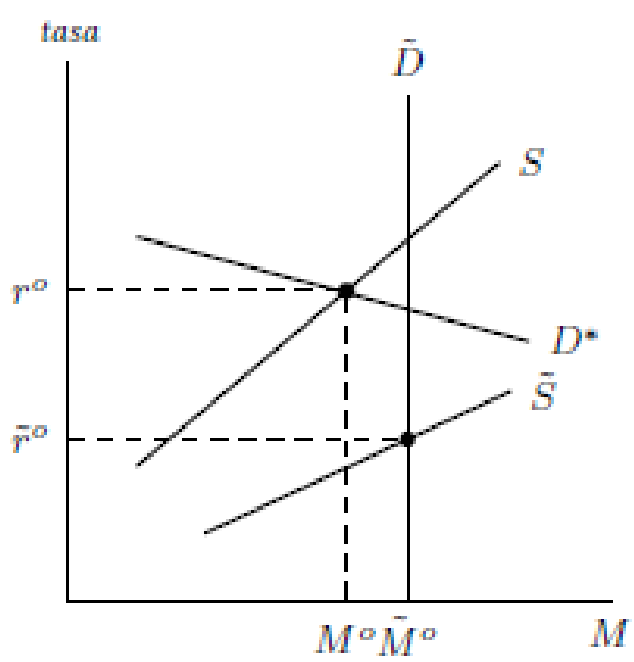

Ilustración 3. El equilibrio del mercado de crédito bancario Fuente: Elaboración propia inspirada en Figueroa (2011).

Es preciso notar que el equilibrio del mercado de crédito bancario excluye a todas aquellas empresas demandantes de crédito que no poseen un ingreso o una dotación de capital suficientemente altos como para solicitar un monto de crédito superior al mínimo requerido por los bancos. Esta demanda de crédito excedente es absorbida por otras instituciones o fuentes de crédito no bancario que siguen siendo formales como los bancos, pero tienen un comportamiento diferente.

\subsection{El sector bancario y las instituciones financieras no bancarias}

Las instituciones financieras no bancarias poseen curvas de oferta y demanda de crédito similares a las de los bancos (Figueroa, 2011). Para capturar los depósitos necesarios para cubrir los créditos que otorgan, estas instituciones recurren a mecanismos diferentes a los usados por los bancos, como exigir depósitos o convertir en socios con derecho a dividendos por ganancia neta a las empresas que soliciten crédito (Ray, 2003). Además, son capaces de otorgar montos de crédito más bajos que los bancos debido a que el tipo de relación que establecen con las empresas asume un carácter más personal, disminuyendo los costos de transacción tanto para otorgar los créditos como para hacer valer las garantías. Sin embargo, el riego que implica financiar a empresas más pequeñas incrementa la posibilidad de incumplimiento del pago de crédito, por lo que suelen cobrar tasas de interés más altas que las de los bancos.

Se puede afirmar que en el mercado crediticio el sector bancario coexiste con el sector financiero no bancario originando una estructura dual del mercado de crédito en la que el equilibrio de este último sector es una consecuencia del equilibrio del sector bancario (Figueroa, 2011). No obstante, dadas las razones antes mencionadas, la tasa de interés cobrada en el sector financiero no bancario, , es superior a la cobrada en el sector bancario, , (ver Ilustración 4). Además, se 
observa que la tasa de interés que se paga por los depósitos en el sector financiero no bancario, , es superior a la que se paga en el sector bancario, , puesto que los usuarios de este sector desempeñan un rol más parecido al de un socio o accionista en relación a la institución crediticia.

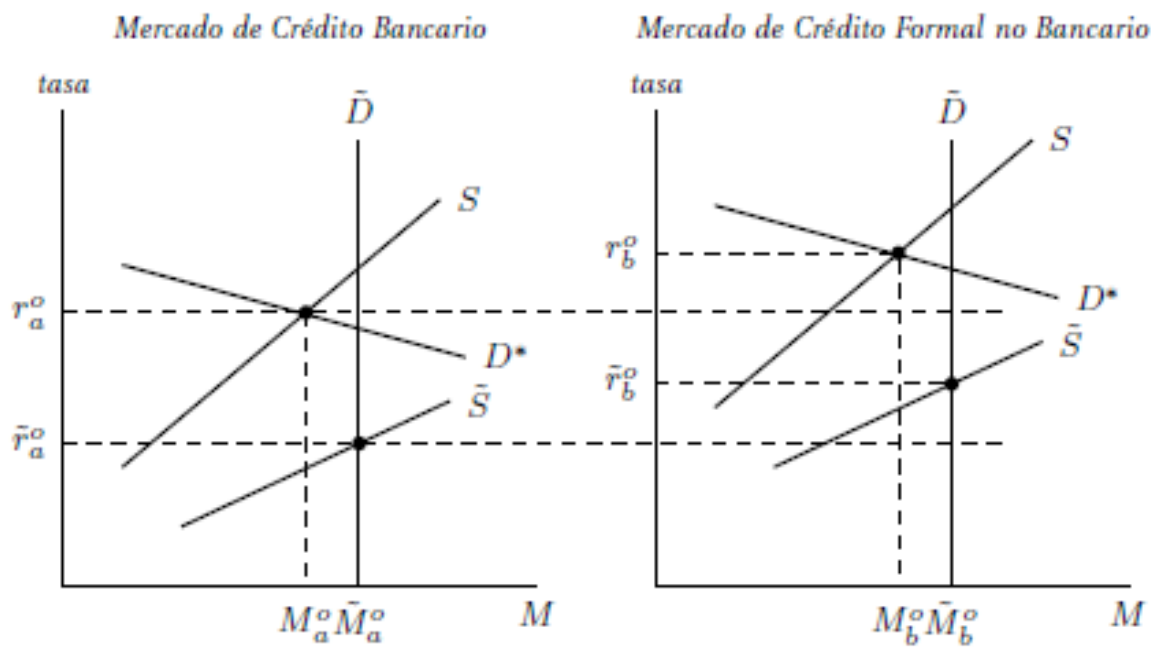

Ilustración 4. El equilibrio de los mercados de crédito bancario y formal no bancario Fuente: Elaboración propia inspirada en Figueroa (2011).

\subsection{Las fuentes informales de crédito}

Incluso con la presencia de los sectores formal bancario y formal no bancario, existen empresas que quedan excluidas de estos mercados de crédito, cuya demanda recae en el denominado sector informal de crédito (Figueroa, 2011). Estos usuarios de crédito normalmente poseen pocos activos o ninguno, por lo que los tipos de acuerdos establecidos con los prestamistas son totalmente distintos a los que se establecen en los mercados formales de crédito. Las fuentes informales de crédito se caracterizan por su naturaleza altamente personalizada, que permite a los prestamistas de este sector cubrir de manera más eficiente los problemas de información limitada en relación a las fuentes formales (Ray, 2003). Además, estos prestamistas suelen aceptar formas de garantías no tradicionales que en un mercado formal serían inadmisibles como, por ejemplo, la posibilidad de que una persona ponga en garantía su propio trabajo como respaldo ante la posibilidad de no poder asumir el pago del crédito. Así entonces, las transacciones crediticias en el sector informal de crédito suelen estar vinculadas a intercambios en otros mercados como los de trabajo, productos y tierra, por lo que los intereses cobrados por dichos préstamos no necesariamente adquieren una forma monetaria (Ray, 2003).

No obstante, a pesar de la condición monetaria o no monetaria de los tipos de interés en el sector de crédito informal, estos suelen ser muy altos debido, por un lado, a la elevada posibilidad de impago a la que se enfrentan los prestamistas, y por otro, a la no existencia de instituciones formales que establezcan mecanismos 
explícitos para exigir las garantías (Ray, 2003). En este sentido, el mecanismo que utiliza el prestamista para exigir el pago del crédito y sus respectivos intereses se basa principalmente en amenazas de no otorgar créditos en el futuro. Por ello, éstos difícilmente se conceden para financiar capital fijo y se encuentran altamente racionados con el objeto de aumentar las posibilidades de que el prestatario necesite otros créditos posteriores (Ray, 2003).

De este modo, vemos que la naturaleza dual del mercado de crédito formal origina un sector informal que absorbe a todos aquellos demandantes de crédito con ingresos bajos y poca o nula dotación de capital excluidos de los sectores bancario y formal no bancario. Este sector se caracteriza por poseer altos costos, monetarios o no monetarios, para los prestatarios. Además, fomenta su dependencia crediticia y, por ende, limita su desarrollo productivo.

En la siguiente sección se determina si este patrón de segmentación del mercado crediticio, según el tipo de institución fuente y la dotación de recursos de las unidades productivas, es consistente con la dinámica de acceso a crédito de los productores de plátano en Nicaragua. Concretamente, se busca evidencia de la existencia o no de algún tipo de vínculo entre la dotación de recursos de los productores del sector platanero y el tipo de fuente de crédito a la que tienen acceso.

\section{El sector agrícola y el mercado de crédito en Nicaragua}

A pesar de que Nicaragua se ha caracterizado históricamente por ser un país predominantemente agrícola, el aporte de este sector a la economía es débil debido a fuertes limitaciones estructurales como: baja productividad, carencia de mano de obra cualificada, generación de poco valor agregado, altos niveles de desigualdad de ingresos y fuertes restricciones de financiamiento. Según datos del Banco Central de Nicaragua (BCN), para el período comprendido entre 2006 y 2013 el sector agrícola representó únicamente el $7.3 \%$ del valor agregado bruto y otorgó un aporte promedio de $0.19 \%$ al crecimiento económico anual. Este escenario evidencia la necesidad de implementar mecanismos que den lugar a transformaciones sustanciales del sistema productivo agrícola, haciendo énfasis en los grupos de productores con mayores limitaciones de recursos, aspecto en el que el crédito constituye un factor indispensable (Padilla-Pérez \& Fenton, 2013). Seguidamente se analizará la dinámica del crédito al sector agrícola por parte de las instituciones crediticias formales, haciendo énfasis en el hecho de que el otorgamiento de crédito principalmente a las actividades con alto potencial de crecimiento es fundamental para lograr el desarrollo del sector.

Es notorio que, aún bajo el panorama adverso al que se enfrenta el sector agrícola nicaragüense, existen algunas actividades pertenecientes a dicho sector económico que han presentado dinámicas de crecimiento muy llamativas. Su estudio debe adquirir un carácter prioritario para el proceso de construcción de políticas para el mejoramiento de las capacidades productivas y los niveles de vida en el campo. El cultivo del plátano constituye un ejemplo de este tipo de actividades. Según datos de la Organización de las Naciones Unidades para la Alimentación (FAO, por sus siglas en inglés), la producción anual de este cultivo pasó de 40,000 toneladas en el año 2000 a 66,000 toneladas en el año 2012. Por su parte, la expansión de las 
exportaciones ha sido aún más destacada, pasando de cero toneladas exportadas en el año 2000 a 40,000 toneladas en el año 2011. Es probable que sea esta dinámica del mercado externo la que esté impulsando y revolucionando la producción del sector platanero, como lo evidencia el hecho de que el rendimiento de este cultivo, evaluado a partir de la cantidad de hectogramos por hectárea, logró un crecimiento de $8.5 \%$ para el año 2012 en comparación al año 2010.

Sin embargo, el impulso de cultivos emergentes de amplio potencial productivo se ve limitado ciertamente por los mismos problemas estructurales a los que se enfrenta el sector agrícola en su conjunto. Sobre esto, Alimo, Fajnzylber, Guasch, López y Oviedo (2009) sostienen que el financiamiento a los productores agrícolas se ha posicionado como una de las alternativas más viables para mejorar las condiciones del sector, permitiendo el acceso a programas de inversión y nuevas tecnologías que estimulen un crecimiento alto y sostenibles de la producción. No obstante, es evidente que las posibilidades de financiamiento están estrictamente vinculadas con el estado del mercado de crédito en relación a aspectos como los niveles de incertidumbre, costos financieros y procesos burocráticos. Por ende, se debe analizar las características del sistema crediticio nicaragüense y su vínculo con el sector agrícola.

En Nicaragua el mercado de crédito formal regulado está compuesto por seis bancos y dos financieras, todos supervisados por la Superitendencia de Bancos y Otras Instituciones Financieras (SIBOIF). Además existe un gran número de otro tipo de instituciones crediticias como microfinancieras o cooperativas de ahorro y crédito que poseen poca o nula regulación por parte del Estado. El carácter no regulado de este gran número de instituciones crediticias imposibilita la obtención de información relacionada a sus operaciones en el mercado de crédito. Por lo tanto, el resto del análisis de enfocará en las instituciones bancarias, las cuales dominan el mercado de crédito regulado.

Uno de los mayores problemas a los que se enfrenta el sector agrícola es la poca disponibilidad de recursos financieros. Según datos de la SIBOIF, para el período comprendido entre 2008 y 2013, el crédito al sector agrícola representó apenas un $10.2 \%$ de la cartera total, mientras que el crédito otorgado para actividades comerciales y/o de consumo representó el 56\%. Así, el sector agrícola es uno de los sectores con mayores restricciones de financiamiento bancario, lo que probablemente se deba a la posición geográfica y los bajos niveles de ingreso y de posesión de capital de la mayoría de los productores (Castro \& Jayme, 2008).

Por otro lado, la crisis bancaria por la que atravesó el país entre los años 20002002 y que provocó la desaparición de muchas de estas entidades, originó un proceso de concentración que ha promovido fuertes prácticas anticompetitivas, generando, entre otras cosas, altos costos de financiación (Asorena, 2007). Como se muestra en la Ilustración 5, durante el período comprendido entre 2011 y 2013 las tasas de interés sobre los préstamos para el sector agrícola, ganadería, silvicultura y pesca, en córdobas - moneda nacional-y en dólares - moneda extranjera-, fueron superiores al 8\%. Además, a los costos relacionados a las tasas de interés debe añadirse un 5\% vinculado a la política de devaluación del córdoba frente al dólar establecida por el Banco Central desde el año 2004, costo que adquiere un carácter explícito mediante cláusulas de mantenimiento de valor. Así, la alta concentración bancaria y la política 
cambiaria hacen muy costoso al crédito bancario, sobre todo para los pequeños y medianos productores con limitada dotación de recursos.

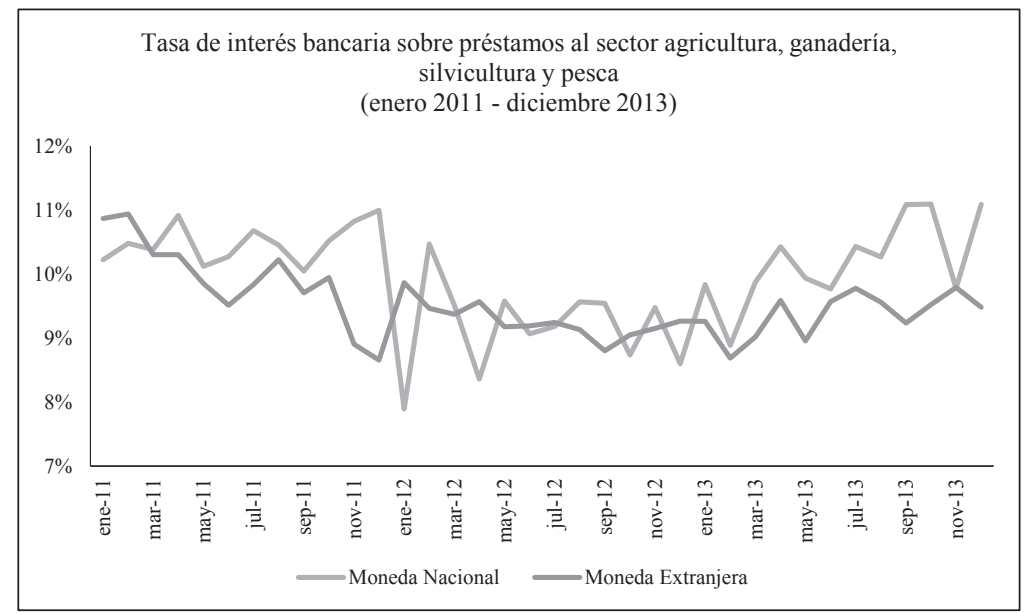

Ilustración 5. Tasas de interés de los préstamos al sector agrícola en Nicaragua Fuente: Elaboración propia con datos del BCN.

Además deloanterior, los bancos nacionales han adquirido un comportamiento discriminatorio frente a las solicitudes de préstamo bajo criterios asociados con el tamaño. En el Cuadro 1 se observa que a partir de los años posteriores a la crisis financiera de 2009, el crédito agrícola ha tendido a desvincularse de las demandas de montos pequeños de crédito, principalmente de aquellos no superiores a los C\$100 mil y los \$25 mil, reasignando dichos recursos a préstamos más grandes y superiores a C $\$ 1$ millón y $\$ 100$ mil. Esto se debe a que los préstamos pequeños son catalogados como más riesgosos.

Cuadro 1. Distribución del crédito agrícola por monto.

\begin{tabular}{|c|c|c|c|c|c|c|}
\hline \multicolumn{7}{|c|}{ Porcentaje de préstamos en miles de córdobas } \\
\hline Préstamo & 2008 & 2009 & 2010 & 2011 & 2012 & 2013 \\
\hline Menores de C\$100 & $93.0 \%$ & $92.0 \%$ & $78.4 \%$ & $60.1 \%$ & $59.9 \%$ & $62.4 \%$ \\
\hline $\mathrm{C} \$ 100-\mathrm{C} \$ 1,000$ & $6.4 \%$ & $4.5 \%$ & $16.9 \%$ & $29.6 \%$ & $29.1 \%$ & $28.9 \%$ \\
\hline$C \$ 1,000-C \$ 6,000$ & $0.6 \%$ & $1.5 \%$ & $4.6 \%$ & $9.9 \%$ & $10.4 \%$ & $8.5 \%$ \\
\hline$C \$ 6,000-C \$ 10,000$ & $0.0 \%$ & $0.1 \%$ & $0.1 \%$ & $0.4 \%$ & $0.2 \%$ & $0.1 \%$ \\
\hline Mayores de $\mathrm{C} \$ 10,000$ & $0.0 \%$ & $0.0 \%$ & $0.0 \%$ & $0.1 \%$ & $0.4 \%$ & $0.1 \%$ \\
\hline \multicolumn{7}{|c|}{ Porcentaje de préstamos en miles de dólares } \\
\hline Préstamo & 2008 & 2009 & 2010 & 2011 & 2012 & 2013 \\
\hline Menores de $\$ 25$ & $84.0 \%$ & $81.7 \%$ & $70.8 \%$ & $67.9 \%$ & $64.7 \%$ & $58.6 \%$ \\
\hline$\$ 25-\$ 100$ & $10.8 \%$ & $12.6 \%$ & $19.5 \%$ & $21.9 \%$ & $24.2 \%$ & $27.0 \%$ \\
\hline$\$ 100-\$ 600$ & $4.7 \%$ & $5.0 \%$ & $8.2 \%$ & $8.7 \%$ & $9.6 \%$ & $12.5 \%$ \\
\hline$\$ 600-\$ 1,000$ & $0.2 \%$ & $0.3 \%$ & $0.8 \%$ & $0.7 \%$ & $0.7 \%$ & $0.8 \%$ \\
\hline Mayores de $\$ 1,000$ & $0.3 \%$ & $0.4 \%$ & $0.6 \%$ & $0.7 \%$ & $0.8 \%$ & $0.1 \%$ \\
\hline
\end{tabular}

Fuente: Elaboración propia con datos del BCN. 
En resumen, se observa que el crédito bancario al sector agrícola se encuentra en un período de transición a carteras de crédito más concentradas en grandes préstamos, altas tasas de interés y fuertes racionamientos, promoviendo un proceso de progresiva segmentación en el que los pequeños y medianos productores quedan excluidos del crédito bancario. Es evidente la necesidad de identificar a nivel más desagregado la relevancia de las características de las unidades productivas en el acceso a fuentes de financiamiento alternativas, sobre todo en las actividades agrícolas con alto potencial productivo, como es el caso de la producción de plátano. Para ello, en las siguientes secciones del artículo se presenta una tipología basada en la dotación de capital tierra y de mano de obra, características productivas y métodos de comercialización de los que dispone una muestra de productores dedicados a esta actividad.

\section{Metodología}

\subsection{Fuente de los datos}

Los datos utilizados provienen del Censo Nacional Agropecuario (CENAGRO) aplicado en Nicaragua en el año 2011, disponibles en la página web oficial del Instituto Nacional de Información y Desarrollo - INIDE (www.inide.gob.ni). Esta base de datos contiene información de 246,556 explotaciones agropecuarias (EAs), de las cuales se seleccionaron para este estudio solamente aquellas que cumplían con los siguientes criterios: que el cultivo del plátano cubriera más del $50 \%$ de su superficie total ${ }^{1}$, que el método de explotación agropecuaria fuera individual productor individual-, y que se hubiera solicitado algún tipo de crédito agrícola para operar. Utilizando estos criterios para identificar a los productores de plátano, se obtuvo un total de 597 EAs que en su mayoría pertenecen a la región del pacífico de Nicaragua ${ }^{2}$ (ver Ilustración 6).

\footnotetext{
1 Se utilizó este criterio de proporcionalidad y no un criterio de extensión de siembra para tratar de aminorar los sesgos vinculados a la naturaleza del proceso de recolección de datos en el CENAGRO, en el que la mayoría de la información de las características productivas de las EAs se recopila sin hacer una desagregación por cultivo. Por ejemplo, si un productor que sembró cinco cultivos distintos reportó haber utilizado algún tipo de agroquímico en su EA, es imposible determinar si éste lo usó en un solo cultivo, parte de ellos o en su conjunto. Así, este criterio aumenta las probabilidades de que la tecnología productiva con la que cuenta la EA sea aplicada al cultivo del plátano.

2 Se obtuvo un total de 606 EAs que cumplian con los criterios mencionados. Sin embargo, nueve fueron consideradas unidades atípicas y, por ende, excluidas del análisis para evitar sesgos en los resultados. Por un lado, siete de estas nueve EAs reportaron haber contratado a más de 50 trabajadores temporales teniendo una extensión no mayor a 15 manzanas de tierra, lo que posiblemente se deba a errores de recopilación de información. Por otro lado, las dos EAs restantes poseian una extensión de 180 manzanas o más, muy superior a la media del resto de unidades.
} 


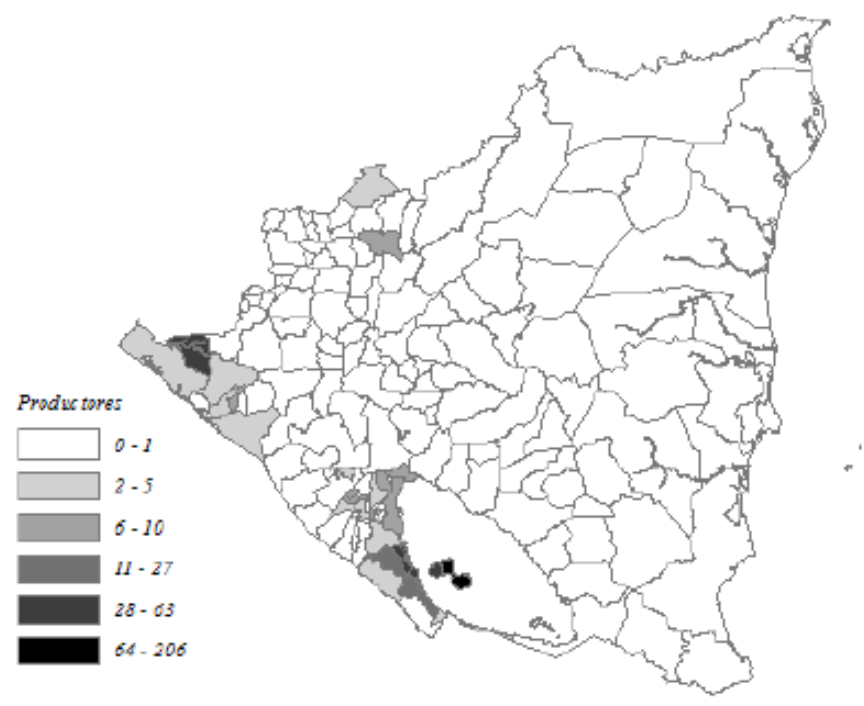

Ilustración 6. Distribución por municipio de los productores analizados Fuente: Elaboración propia

\subsection{Procesamiento de los datos}

Se recolectó un total de 12 variables relacionadas a cada EA, las que a su vez fueron distribuidas en siete categorías:

1 Tierra, que contiene información sobre el tamaño de la EA y el área cultivada con plátano.

2 Mano de obra, que contiene información sobre el número de trabajadores temporales y permanentes que el productor contrató para dicho ciclo agrícola.

3 Comercio, que contiene información sobre el fin último que el productor da a su cosecha.

4 Semilla, que contiene información sobre la calidad de la semilla que se utiliza.

5 Sistema de riego, que contiene información sobre si el productor utiliza un sistema de riego y de qué tipo.

6 Agroquimicos, que contiene información sobre la utilización de productos químicos u orgánicos que el productor utiliza para mejorar el rendimiento de su plantación.

7 Crédito, que contiene información sobre el tipo de fuente de crédito a la que tuvo acceso el productor, en caso de haber recibido.

\subsubsection{Dotación de capital y características de la tecnología productiva y de comercialización}

Las categorías (1) y (2) contienen variables de naturaleza continua cuyo objetivo es medir la dotación de capital tierra y capital trabajo del que dispone el productor (ver Cuadro 2). Se entiende que la dotación inicial de estos factores, sobre todo de la tierra, es un elemento diferenciador fundamental entre productores. 
Cuadro 2. Dotación de capital tierra y capital trabajo

\begin{tabular}{lll}
\hline Categoría & Variable & Contenido \\
\hline \multirow{2}{*}{ (1) Tierra } & Tamaño de la EA & Tamaño en manzanas de la EA. \\
& Área sembrada & Área en manzanas cultivadas con plátano de la EA. \\
& Permanentes & $\begin{array}{l}\text { Número de trabajadores permanentes } \\
\text { (2) Mano }\end{array}$ \\
de obra & Temporales & $\begin{array}{l}\text { Número de trabajadores temporales contratados para } \\
\text { trabajar durante el ciclo agrícola }\end{array}$ \\
\hline
\end{tabular}

Fuente: Elaboración propia.

Para las categorías comprendidas entre (3) y (6) se crearon variables de naturaleza dicótoma basadas en los criterios mostrados en el Cuadro 3. La categoría (3) busca medir los mecanismos de comercialización de los que dispone el productor bajo el supuesto de que aquellos que venden su cosecha perciben mayores beneficios que aquellos que la utilizan para autoconsumo. ${ }^{3}$ Las categorías (4), (5) y (6) buscan medir la tecnología productiva con la que cuenta la EA, bajo el precepto de que la utilización de semilla con altos estándares de rendimiento, la posesión de un sistema de riego tecnificado y la implementación de sustancias químicas u orgánicas para mejorar el rendimiento del cultivo, son características fundamentales para identificar el tipo de estructura productiva con la que cuentan los productores.

Cuadro 3. Tecnología productiva y de comercialización

\begin{tabular}{|c|c|c|c|}
\hline Categoría & Variable & \multicolumn{2}{|c|}{ Característica } \\
\hline \multirow{2}{*}{ (3) Comercio } & \multirow{2}{*}{ Venta } & 1 & cuando el productor vende su cosecha. \\
\hline & & $\mathrm{C}$ & cuando la utiliza para consumo personal. \\
\hline \multirow[t]{2}{*}{ (4) Semilla } & \multirow[t]{2}{*}{ Semilla } & 1 & $\begin{array}{l}\text { cuando el productor utiliza semilla mejorada o } \\
\text { semilla certificada. }\end{array}$ \\
\hline & & 0 & cuando no. \\
\hline \multirow{2}{*}{$\begin{array}{l}\text { (5) Sistema de } \\
\text { riego }\end{array}$} & \multirow[t]{2}{*}{ Riego } & 1 & $\begin{array}{l}\text { cuando el productor utiliza sistema de riego por } \\
\text { aspersión, goteo o gravedad }\end{array}$ \\
\hline & & $\mathrm{C}$ & cuando no. \\
\hline \multirow{8}{*}{ (6) Agroquímicos } & \multirow[t]{2}{*}{ Fertilizante } & 1 & $\begin{array}{l}\text { cuando el productor utiliza fertilizantes o abono } \\
\text { orgánico. }\end{array}$ \\
\hline & & c & cuando no. \\
\hline & \multirow{2}{*}{ Insecticida } & 1 & cuando el productor utiliza insecticida. \\
\hline & & c & cuando no. \\
\hline & \multirow{2}{*}{ Fungicida } & 1 & cuando el productor utiliza fungicida. \\
\hline & & c & cuando no. \\
\hline & \multirow{2}{*}{ Herbicida } & 1 & cuando el productor utiliza herbicida. \\
\hline & & $\mathrm{c}$ & cuando no. \\
\hline
\end{tabular}

Fuente: Elaboración propia.

3 En el CENAGRO no existe información sobre cómo ni a quien vende el productor, razón por la que se toma la venta o no del producto como única variable para representar el factor comercio. 


\subsubsection{Análisis de componentes principales}

Dado el gran número de variables involucradas en el análisis, se utilizó el método PCA (Principal Component Analysis) con el objetivo de redimensionar el conjunto inicial de variables a unos cuantos componentes principales que contendrán gran parte de su información (Rencher \& Christensen, 2012). El PCA, propuesto por Pearson (1901) y por Hotelling (1933), permite encontrar aquellas combinaciones lineales -componentes- de un conjunto inicial de variables que re-distribuyen su varianza de tal manera que los primeros componentes contienen la mayor parte de su información. Así entonces, el PCA se realizó a partir de la matriz de correlación de las variables comprendidas en las categorías (1) a (6), que contiene información sobre la dotación de capital tierra y capital trabajo, y la tecnología productiva y de comercialización con la que cuenta la EA. ${ }^{4}$ Con ello se busca obtener un número pequeño de nuevas variables que contengan la mayor parte de la información relevante contenida en el grupo inicial de variables.

En el Cuadro 4 se pueden observar los valores propios estimados a partir de la matriz de correlación, los cuales brindan información sobre la proporción de la varianza total del conjunto de variables originales explicada por el -ésimo componente principal. Utilizando el criterio propuesto por Cattell (1966), se seleccionaron los componentes principales cuyo valor propio fuera superior a su media aritmética, que en nuestro caso es igual a uno puesto que se utilizó una matriz de correlaciones para su cálculo. De este modo, se seleccionaron los primeros cuatro componentes principales que a su vez explican aproximadamente el 70\% de la varianza total.

Cuadro 4. Valores propios de la matriz de correlación

\begin{tabular}{lccc}
\hline \multicolumn{1}{c}{ Componente } & Valor propio & Varianza explicada & Varianza acumulada \\
\hline Comp 1 & 3.521 & $32.0 \%$ & $32.0 \%$ \\
Comp 2 & 1.746 & $15.8 \%$ & $47.8 \%$ \\
Comp 3 & 1.188 & $10.8 \%$ & $58.6 \%$ \\
Comp 4 & 1.145 & $10.4 \%$ & $69.1 \%$ \\
Comp 5 & 0.873 & $7.9 \%$ & $77.0 \%$ \\
Comp 6 & 0.830 & $7.5 \%$ & $84.6 \%$ \\
Comp 7 & 0.756 & $6.8 \%$ & $91.4 \%$ \\
Comp 8 & 0.421 & $3.8 \%$ & $95.3 \%$ \\
Comp 9 & 0.307 & $2.7 \%$ & $98.1 \%$ \\
Comp 10 & 0.177 & $1.6 \%$ & $99.7 \%$ \\
Comp 11 & 0.032 & $0.2 \%$ & $100.0 \%$ \\
\hline
\end{tabular}

Fuente: Elboración propia.

\footnotetext{
4 Puesto que en este conjunto de variables existen tanto variables discretas como continuas, la matriz de correlación fue calculada utilizando los indices Polychoric y Polyserial propuestos por Kolenikov y Angeles (2004) que permiten estimar correlaciones entre variables discretas y entre variables continuas y discretas, respectivamente.
} 
Los vectores propios utilizados para calcular los cuatro componentes principales seleccionados se muestran en el Cuadro 5. Estos componentes fueron incluidos en un análisis de clusters para tratar de identificar patrones en los datos que evidenciaran la existencia o no de agrupaciones de productores con similares características productivas, de comercialización y de dotación de capital.

Cuadro 5. Vectores propios de la matriz de correlación

\begin{tabular}{lrrrr}
\hline Variables & Comp 1 & Comp 2 & Comp 3 & Comp 4 \\
\hline Tierra & 0.324 & -0.568 & -0.066 & -0.047 \\
Área sembrada & 0.333 & -0.560 & -0.086 & -0.047 \\
Permanentes & 0.383 & -0.107 & -0.081 & -0.039 \\
Temporales & 0.239 & -0.021 & 0.215 & 0.383 \\
Venta & 0.173 & -0.043 & 0.426 & 0.498 \\
Semilla & 0.154 & 0.156 & -0.157 & 0.615 \\
Riego & 0.339 & 0.311 & -0.414 & 0.057 \\
Fertilizante & 0.227 & 0.271 & 0.246 & 0.012 \\
Insecticida & 0.403 & 0.254 & 0.034 & -0.210 \\
Fungicida & 0.405 & 0.286 & -0.169 & -0.251 \\
Herbicida & 0.175 & 0.080 & 0.682 & -0.328 \\
\hline
\end{tabular}

Fuente: Elaboración propia.

\subsubsection{Tipo de fuente de crédito}

La categoría (7) contiene una variable de naturaleza categórica creada en base a los criterios mostrados en el Cuadro 6. Esta variable es parte fundamental de la investigación, ya que con base a ella se determinará si la dotación de capital y la tecnología productiva y de comercialización con la que cuenta la EA son determinantes sustantivos del tipo de fuente de crédito al que tiene acceso. Sin embargo, una de las debilidades en cuanto al método de recolección de información por parte del CENAGRO fue la de no establecer una distinción explícita entre el hecho de que el productor haya recibido un crédito de un banco privado o de una microfinanciera. Esto impide determinar si éste tuvo acceso a una fuente bancaria o formal no bancaria de acuerdo a nuestra clasificación de las fuentes de crédito. 
Cuadro 6. Tipo de fuente de crédito

\begin{tabular}{ll}
\hline Categoría Variable & Característica \\
\hline 0 & No le fue concedido el crédito (excluido) \\
& Si la fuente de crédito fue un prestamista, acopiador u \\
& ONG (crédito informal) \\
& Si la fuente de crédito fue una microfinanciera, caja rural, \\
Crédito Fuente de crédito $\quad \begin{array}{l}\text { cooperativa de ahorro y crédito, empresa, casa comercial } \\
\text { o un programa o proyecto del gobierno (crédito formal no } \\
\text { bancario) } \\
\text { Si la fuente de crédito fue un banco comercial o el banco } \\
\text { Produzcamos (crédito bancario) }\end{array}$ \\
\hline
\end{tabular}

Fuente: Elaboración propia.

Para solucionar este problema se utilizó el método LDA (Linear Discrimitation Analysis), desarrollado por Fisher (1936) y Mahalanobis (1936), el cual permite determinar la pertenencia o no de determinado sujeto a un grupo previamente establecido. Con el método LDA es posible comparar los grupos conformados por los productores que reportaron haber accedido a un crédito bancario -que orginalmente incorpora a aquellos productores que accedieron a una microfinanciera- y los que accedieron a un crédito formal no bancario, y determinar cuáles de los productores que reportaron haber tenido acceso a un crédito bancario probablemente lo hicieron a través de una microfinanciera. Esta re-localización de productores del mercado de crédito bancario hacia el mercado formal no banario se basa en el supuesto de que los prodctores que poseen características similares a aquellos que reportaron haber obtenido un crédito del sector formal no bancario, difícilmente pudieron haber tenido acceso al sector bancario privado.

El LDA fue aplicado a los cuatro componentes principales calculados anteriormente mediante el PCA y los resultados se muestran en su correspondiente tabla de clasificación (ver Cuadro 7) calculada de manera que el sector formal no bancario posee mayor prioridad que el sector bancario, considerando el hecho de que es más difícil acceder a este último. La tabla de clasificación muestra cómo los productores que accedieron a los sectores bancario o formal no bancario -grupo original- fueron re-clasificados al sector al que probablemente tuvieron acceso en función de sus características -grupo predicho. Los elementos de la diagonal principal son aquellos productores que, aún después del proceso de re-clasificación, siguieron perteneciendo a su respectivo grupo original, mientras que aquellos que están fuera de la diagonal principal pasaron de pertenecer a un sector a formar parte de otro. Se re-clasificaron únicamente aquellos productores que en un principio pertenecían al sector bancario y fueron re-asignados al sector formal no bancario, que en este caso fueron 348. 
Cuadro 7. Tabla de clasificación por tipo de fuente de crédito

\begin{tabular}{lccc}
\hline \multirow{2}{*}{ Grupo original } & \multirow{2}{*}{ Observaciones } & \multicolumn{2}{c}{ Grupo predicho } \\
\cline { 3 - 4 } & & Bancario & Formal no bancario \\
\hline Bancario & 424 & 76 & 348 \\
Formal no bancario & 86 & 5 & 81 \\
Prioridades & & 0.4 & 0.6 \\
\hline
\end{tabular}

Fuente: Elaboración propia.

\section{Discusión de los resultados}

\subsection{Análisis de clusters}

El CA (Cluster Analysis) permite identificar patrones en un conjunto de datos creando agrupaciones -clusters- cuyas observaciones u objetos poseen características similares a lo interno del grupo, pero diferentes a lo externo del mismo (Rencher \& Christensen, 2012). Así, los cuatro componentes principales obtenidos en la sección anterior fueron sometidos al método de clusterización jerárquica propuesto por Ward (1963) con el objetivo de crear una tipología de productores basada tanto en la dotación de capital como en la tecnología productiva y distributiva que poseen.

Los resultados del CA se muestran en el dendrograma presentado en la Ilustración 7, construido en base a un total de 15 ramificaciones (). Éste muestra cláramente la existencia de tres agrupaciones importantes de productores: la agrupación , que abarca las ramas, que contiene a 299 productores; la agrupación , formada por las ramas que contiene a 236 productores; y la agrupación , formada por las ramas, que contiene a 62 productores.

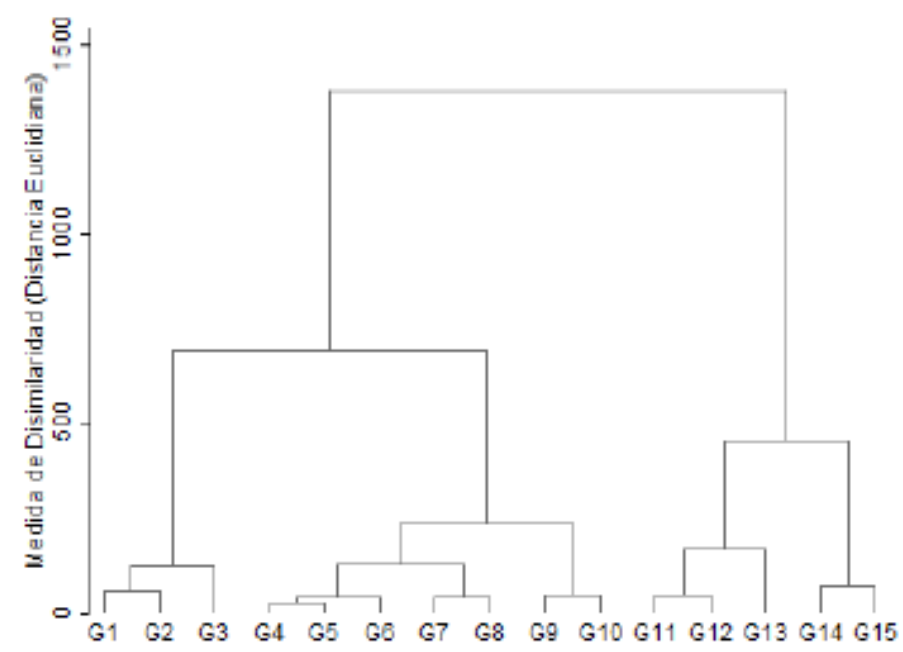

Ilustración 7. Dendrograma del análisis de clusters

Fuente: Elaboración propia. 
Se trabajará en base a los tres grupos de productores que se obtuvieron mediante el CA, clasificados en orden de secuencia como grupo , grupo y grupo , según los resultados del dendrograma (ver Cuadro 8). Las características principales de cada grupo serán utilizadas para crear un tipología de productores que permita comprobar si existe un vínculo explícito entre este factor y el tipo de fuente de crédito a la que se accede.

Cuadro 8. Número de productores por grupo

\begin{tabular}{lll}
\hline Grupo & Productores & Proporción \\
\hline A & 299 & $50.1 \%$ \\
B & 236 & $39.50 \%$ \\
C & 62 & $10.40 \%$ \\
Total & 597 & $100.0 \%$ \\
\hline
\end{tabular}

Fuente: Elaboración propia.

\subsection{Caracterización y tipología de productores}

Los grupos muestran una marcada diferenciación en relación a la dotación de capital tierra y capital trabajo del que disponen (ver Cuadro 9.). En relación al capital tierra, los productores que pertenecen al grupo siembran en promedio un total de $1.3 \mathrm{mz}$, muy inferior a las $5.6 \mathrm{mz}$ y $16.2 \mathrm{mz}$ que siembran los productores de los grupos y, respectivamente. Esto demuestra la presencia de fuertes desigualdades en cuanto a la tenencia de la tierra. En relación al capital trabajo, se observa que los productores de los grupos y no son, en promedio, capaces de contratar mano de obra permanente, en cambio, los productores del grupo sí lo son. Además, los grupos que poseen menores extensiones de tierra tienden a contratar menor cantidad de mano de obra temporal, lo que es consistente con el hecho de que los productores con EAs más pequeñas suelen usar su propio trabajo y el de sus familias para desarrollar sus actividades agrícolas.

Cuadro 9. Distribución de capital tierra y capital trabajo por grupos de productores

\begin{tabular}{|c|c|c|c|c|}
\hline \multirow{2}{*}{ Grupo } & Tamaño EA & Área sembrada & Permanentes & Temporales \\
\hline & \multicolumn{2}{|c|}{ manzanas promedio } & \multicolumn{2}{|c|}{ trabajadores promedio } \\
\hline A & 1.7 & 1.3 & 0.3 & .2 \\
\hline B & 5.6 & 4.3 & 0.9 & .3 \\
\hline $\mathrm{C}$ & 22.2 & 16.2 & 4 & 5 \\
\hline
\end{tabular}

Fuente: Elaboración propia.

Además de las diferencias en cuanto a dotación de capital, los productores de los distintos grupos presentan tecnologías productivas bastante heterogéneas (ver Cuadro 10). En este sentido, la utilización de semilla mejorada o certificada es una práctica muy escaza en los productores de todos los grupos, pero un poco más frecuente en el grupo, donde el $24.2 \%$ de los productores utilizan esta práctica 
agrícola. Por otro lado, el grupo presenta los mayores problemas en cuanto a la utilización de agroquímicos para mejorar la resistencia y calidad de su cultivo, en comparación con los grupos y. También se observan fuertes debilidades en cuanto a la utilización de sistemas de riego tecnificados en todos los grupos, pero sobre todo en los grupos y, donde aproximadamente un 65\% de los productores no cuenta con esta tecnología, evidenciando su susceptibilidad a cambios meteorológicos adversos como las sequías. En conjunto, estos factores no solo merman la capacidad productiva y de generación de ingresos de los productores que poseen menor dotación de capital, sino que también ponen en riesgo la seguridad alimentaria de los sistemas socio-económicos locales en los que se desenvuelven.

Cuadro 10. Caracterización de la tecnología productiva y de comercialización por grupos de productores

\begin{tabular}{lccccccc}
\hline Grupo & Venta & Semilla & Riego & Fertilizante & Insecticida & Fungicida & Herbicida \\
\hline A & $73.6 \%$ & $13.7 \%$ & $32.8 \%$ & $80.9 \%$ & $57.5 \%$ & $42.8 \%$ & $66.9 \%$ \\
B & $87.7 \%$ & $13.6 \%$ & $35.6 \%$ & $84.7 \%$ & $72.0 \%$ & $50.4 \%$ & $85.2 \%$ \\
C & $85.5 \%$ & $24.2 \%$ & $54.8 \%$ & $90.3 \%$ & $88.7 \%$ & $70.1 \%$ & $83.9 \%$ \\
\hline
\end{tabular}

Fuente: Elaboración propia.

La diferencia en cuanto a la dotación de capital tierra es, probablemente, el principal diferenciador entre productores. Como se puede apreciar en la Ilustración 8, el $60 \%$ de las EAs más pequeñas representan únicamente cerca del 20\% de la extensión total de la tierra analizada. Esta diferencia de posesión de tierras podría explicar no solo las diferencias en cuanto a la capacidad de contratación de los productores, sino también aquellas relacionadas con el tipo de tecnología productiva que utilizan. Esto se debe a que los productores con menor extensión de tierra generalmente utilizan su propia mano de obra para producir y, además, son incapaces de aprovechar las economías de escala que genera la incorporación de nuevas tecnologías (Ray, 2003).

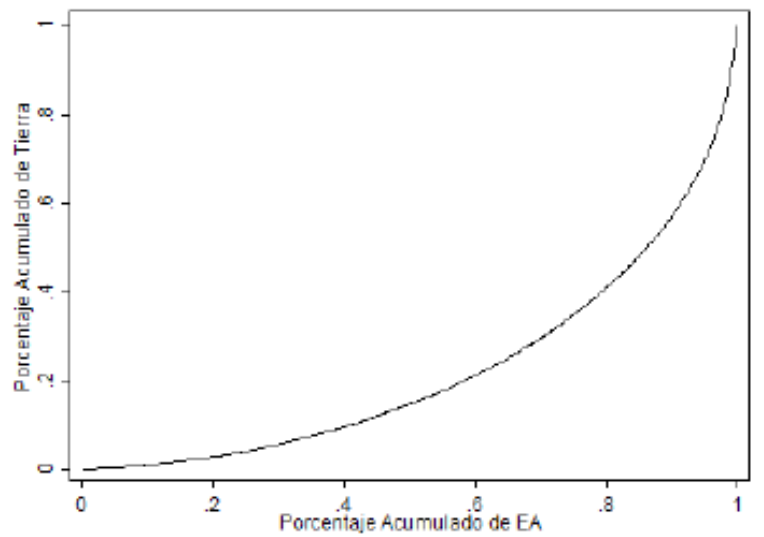

Ilustración 8. Curva de Lorenz de la distribución de la tierra entre productores de plátano

Fuente: Elaboración propia. 
Además de los problemas de distribución de capital y de heterogeneidad productiva, podemos observar que en los diferentes grupos existen dificultades de comercialización, siendo el grupo el más afectado, donde más de un 25\% de los productores no comercializan su producto (ver Cuadro 10). Esta imposibilidad de acceder a mercados que permitan obtener mejores ganancias sobre las cosechas constituye un enorme obstáculo para el fomento y el desarrollo de nuevas capacidades y tecnologías productivas, ya que no existen incentivos para que los pequeños productores inviertan en este tipo de procesos (Bastiaensen \& Marchetti, 2011).

Entonces, con base en las agrupaciones de productores aquí presentadas es posible elaborar una tipología basada no solo en la dotación de capital del que disponen, sino también en su tecnología productiva y de comercialización. Primeramente tenemos al grupo como el grupo de pequeños productores con muy poca tierra, débil poder de contratación, tecnología productiva muy limitada y debilidades para comercializar su producto. Luego tenemos al grupo como el grupo de medianos productores que cuentan con poca tierra, poseen débil capacidad de contratación, tecnología productiva limitada y algunas debilidades para comercializar su producto. Por último, tenemos al grupo como el grupo de productores que cuentan con buenas extensiones de tierra y un relativo poder de contratación, además de contar con tecnologías productivas más desarrolladas en comparación con los productores de los demás grupos, pero que también se enfrentan a problemas de comercialización.

\subsection{Acceso al crédito según tipo de productor}

Dada la tipología de productores presentada en la sección anterior, se procede a analizar la posible relación existente entre las características de los productores estudiados y el sector crediticio al que tienen acceso (ver Cuadro 11). Concretamente, se busca determinar si el grupo al que pertenece un productor es factor determinante para que éste sea excluido del mercado de crédito o pueda acceder a una fuente informal, formal no bancaria o bancaria.

Cuadro 11. Tipos de fuentes de crédito por sector

\begin{tabular}{lll}
\hline Bancaria & Formal no bancaria & Informal \\
\hline Banco Privado & Microfinanciera & Prestamista \\
Banco Produzcamos & Caja rural & Acopiador \\
& Cooperativa de ahorro y crédito & ONG \\
& Programa o proyecto del gobierno & \\
& Empresa & \\
& Casa comercial & \\
\hline
\end{tabular}

Fuente: Elaboración propia.

Teniendo en cuenta el proceso de re-clasificación anterior y su posible repercusión en los resultados, el Cuadro 12 muestra una clara relación entre el tipo de productor y el tipo de fuente de crédito a la que éste tuvo acceso. La mayoría de los productores a los que les fue negado el crédito o accedieron a una fuente de crédito 
informal se encuentran en los grupos y, que son los grupos con mayores debilidades tanto productivas y de comercialización como de dotación de recursos de capital. Por otro lado, puede notarse que en el grupo la proporción de productores que accedieron al sector bancario es mayor que en los demás grupos, lo que evidencia que el acceso al sector bancario se ve restringido por las características que éstos poseen. No obstante, cabe mencionar que el problema del acceso al crédito de los productores individuales de plátano no es tan pronunciado, ya que el $93.6 \%$ de éstos pudo obtener un crédito y el $85.2 \%$ lo hizo a través de una fuente formal, siendo el sector formal no bancario el que más incidencia posee, atendiendo al $72 \%$ de dichos productores.

Cuadro 12. Acceso al crédito por tipo de productor y tipo de fuente de crédito

\begin{tabular}{llllll}
\hline \multicolumn{5}{c}{ Tipo de fuente de crédito } \\
\hline Grupo & Excluido & Informal & Formal no bancario & Bancario & Total \\
\hline \multirow{2}{*}{ A } & 20 & 30 & 232 & 17 & 299 \\
& $6.7 \%$ & $10.0 \%$ & $77.6 \%$ & $5.7 \%$ & $100.0 \%$ \\
B & 17 & 18 & 161 & 40 & 236 \\
& $7.2 \%$ & $7.6 \%$ & $68.2 \%$ & $16.9 \%$ & $100.0 \%$ \\
C & 1 & 2 & 37 & 22 & 62 \\
& $1.6 \%$ & $3.2 \%$ & $59.7 \%$ & $35.5 \%$ & $100.0 \%$ \\
\multirow{2}{*}{ Total } & 38 & 50 & 430 & 79 & 597 \\
& $6.4 \%$ & $8.4 \%$ & $72.0 \%$ & $13.2 \%$ & $100.0 \%$ \\
\hline
\end{tabular}

Fuente: Elaboración propia.

Sin embargo, a pesar del relativo buen acceso a crédito del que gozan los productores de plátano, se observan fuertes debilidades en cuanto al fomento de capacidades que permitan reducir las existentes brechas productivas y de ingreso. Al respecto, se observa que el $70 \%$ de los productores de los grupos y, conformados por los productores más débiles, no reportó haber recibido algún tipo de capacitación o asistencia técnica por parte de la institución que le otorgó el crédito o alguna otra institución pública o privada (ver Cuadro 13). Esto muestra serias debilidades en los mecanismos de financiamiento y, sobre todo, en la política crediticia de estas instituciones, ya que la ausencia de instrumentos que permitan dar seguimiento y apoyo a los productores con mayores limitaciones disminuye drásticamente las posibilidades de que éstos logren una transformación significativa de sus capacidades productivas y mejoren sus condiciones de vida. 
Cuadro 13. Recibimiento de capacitación y/o asistencia técnica de los productores que recibierón crédito según tipo

\begin{tabular}{clll}
\hline \multirow{2}{*}{ Grupo } & \multicolumn{2}{c}{ Recibió asistencia técnica y/o capacitación } & \multirow{2}{*}{ Total } \\
\cline { 2 - 3 } & \multicolumn{1}{c}{ Sí } & 206 & 279 \\
A & 73 & $73.8 \%$ & $100.0 \%$ \\
& $26.2 \%$ & 155 & 219 \\
B & 64 & $70.8 \%$ & $100.0 \%$ \\
& $29.2 \%$ & 26 & 61 \\
C & 35 & $42.6 \%$ & $100.0 \%$ \\
& $57.4 \%$ & 172 & 559 \\
Total & 387 & $30.8 \%$ & $100.0 \%$ \\
\hline
\end{tabular}

Fuente: Elaboración propia.

Vemos entonces que a pesar de las diferencias en la dotación de capital e implementación de tecnologías productivas y de comercialización, los productores de plátano en Nicaragua no presentan a priori problemas muy graves en cuanto al acceso a crédito. Sin embargo, los resultados muestran que existe muy poco seguimiento y fomento de capacidades por parte de las instituciones crediticias involucradas, lo que limita grandemente el efecto positivo que el crédito por sí mismo podría tener sobre el desarrollo tecnológico y el nivel de vida de los productores con pocos recursos. En línea con lo planteado por Bastiaensen y Marchetti (2011), el actuar de las instituciones financieras no debe permanecer ajeno a la dinámica de las cadenas de valor a las que se incertan los productores, sino que se deben establecer mecanismos no financieros que propicien cambios productivos eficientes que permitan una mejor incersión de éstos a mercados más dinámicos para así obtener mayores beneficios y mejoras en los estándares de vida.

\section{Conclusiones}

Dada la dinámica de crecimiento exhibida por el sector platanero nicaragüense en la última década, es clave la elaboración de políticas que permitan transformar dicha expansión en un proceso de desarrollo sostenible e inclusivo que logre mejorar significativamente las condiciones de vida de los productores con escasos recursos. En este proceso, el sistema crediticio nacional desempeña un papel fundamental por ser el mecanismo mediante el cual los productores adquieren los recursos para lograr desarrollar sus actividades. Sin embargo, como se evidencia en el presente estudio, tanto el sector platanero como el sistema crediticio poseen fuertes problemas estructurales que limitan la evolución de dicho proceso de desarrollo.

A nivel general, se observa que las instituciones bancarias otorgan pocos recursos al sector agrícola en relación a otros sectores, como el comercio y el consumo, además de presentar elevadas tasas de interés y una parcialización de dichos créditos hacia los productores con mayor capacidad de pago. $\mathrm{Al}$ respecto, se evidencia que la fuerte desigualdad existente en cuanto a la distribución del ingreso y la dotación de capital provoca que los grupos de productores más vulnerables accedan a las fuentes 
de crédito con mayores costos de financiamiento y con capacidad limitada de otorgamiento de recursos. Los resultados muestran que la mayoría de los productores de plátano con mayores limitaciones de recursos y debilidades productivas, a pesar de presentar un relativamente buen acceso al crédito por no haber muchos problemas de exclusión, no son capaces de acceder al sector formal bancario, que presenta también altos costos de financiamiento, pero inferiores a los costos de las otras fuentes de crédito.

La evidencia muestra que la mayoría de los pequeños y medianos productores de plátano se incorporan al sector formal no bancario principalmente en microfinancieras. No obstante, el acceso o no a fuentes de crédito bancario no implica per se un problema severo, ya que las fuentes formales no bancarias usualmente disponen de tecnologías financieras más adecuadas para la financiación de los productores con menos recursos. El problema radica en que dichas instituciones presentan fuertes debilidades en relación al otorgamiento de servicios complementarios a la financiación que fomenten el desarrollo de las capacidades productivas del segmento de productores al que atienden, como la asistencia técnica y capacitación.

\section{Recomendaciones}

El desarrollo de instituciones crediticias, sobre todo de naturaleza formal no bancaria que brinden de manera eficiente tanto servicios financieros como servicios complementarios, es un factor clave para disminuir las brechas socio-económicas existentes en el campo. La inclusión de estos servicios extra-financieros permite, además de mejorar la utilización y el monitoreo de los recursos monetarios otorgados por la institución crediticia, dinamizar y hacer inclusivos los procesos de transferencia y difusión tecnológica. Como indican Bastiaensen y Marchetti (2011), la actividad de microfinanciación debe incorporar elementos que refuercen y denamicen la inserción de los pequeños productores a cadenas de valor eficientes, y no seguir una ruta de despersonalización de los servicios, actuando más como instituciones bancarias. Además, el conocimiento del entorno local y regional que estas instituciones poseen permite crear instrumentos y mecanismos de apoyo específicos que evitan que el proceso de modernización agrícola sea un factor generador de desigualdad al propiciar la inclusión productiva, sobre todo de los productores que selen ser excluidos tanto de los entornos organizacionales innovadores como de los procesos de aprendizaje y difusión tecnológica (Vieira , 2013).

Por último, dada la relevancia del rol que desempeñan las instituciones crediticas, sobre todo las microfinancieras, en el proceso de financiamiento de los productores del sector platanero, un estudio más específico que incorpore información sobre las dinámicas productivas y organizativas de entornos locales concretos, así como del modus operandi de las instituciones financieras presentes, brindaría un panorama más claro de los problemas a los que se enfrentan en especial los pequeños y medianos productores del sector y, además, permitiría elaborar propuestas de política económica que logren generar sinergias entre los distintos actores involucrados. Como sugiere Yoguel (2000), la clave para generar competencias 
y ventajas competitivas radica en el hecho de que los productores sean capaces de endogenizar el aprendizaje y el conocimiento tecnológico para generar por cuenta propia mayores capacidades productivas, desarrollar cambios organizacionales más eficientes y lograr mejores vínculos con los mercados más dinámicos, aspecto en el que las instituciones crediticias juegan un papel muy importante.

\section{Referencias bibliográficas}

Alimo, V., Fajnzylber, P., Guasch, J., López, J., \& Oviedo, A. (2009). Does The Investment Climate Matter?: Microeconomic Foundations of Growth in Latin America. Washington, DC: The World Bank.

Asorena, C. (2007). Competencia y Regulación en la Banca: El Caso de Nicaragua. México: Naciones Unidas.

Bastiaensen, J., \& Marchetti, P. (2011). Rural microfinance and agricultural value chains: Strategies and perspectives of the Fondo de Desarrollo Local in Nicaragua. In B. Almandariz \& M. Labie (eds.). Handbook of Microfinance (pp. 461-500). Singapore: World Scientific Publishers.

Castro, D. \& Jayme, F. (2008). Consolidación bancaria y concentración del crédito en Brasil (1995-2004). Revista CEPAL, 95, 157-173.

Cattell, R. B. (1966). The screen test for the number of factors. Multivariate Behavioral Research, 1, 157-173.

Figueroa, A. (2011). La desigualdad del ingreso y los mercados de crédito. Revista CEPAL, 105, 39-55.

Fisher, R. A. (1936). The use of multiple measurements in taxonomic problems. Annals of Eugenics, 7, 179-188.

Hotelling, H. (1933). Analysis of a complex of statistical variables into principal components. Journal of Educational Psychology, 24, 417-441.

Kolenikov, S. \& Angeles, G. (2004). The use of discrete data in Principal component analysis with applications to socio-economic indices. CPC/Measure, 4-85.

Levine, R. (1997). Financial develpment and economic growth: views and agenda. Journal of Economic Literature, 35, 688-726.

Mahalanobis, P. C. (1936). On the generalized distance in statistics. National Institute of Science of India, 12.

McCallum, B. (1989). Monetary Economics Theory and Policy. New York: Macmillan Publishing Company.

Padilla-Pérez, R. \& Fenton, R. (2013). Financiamiento de la banca comercial para las micro, pequeñas y medianas empresas en México. Revista CEPAL, 111, 7-21.

Pearson, K. (1901). On lines and planes of closest fit to systems of points in space. Philosophical Magazine, 62, 559-572.

Ray, D. (2003). Economía del Desarrollo. Barcelona: Antoni Bosch Editor.

Rencher, A. C. \& Christensen, W. F. (2012). Methods of Multivariate Analysis (3rd ed.). Hoboken, NJ: Wiley.

Vieira , J. (2013). Heterogeneidad estructural de la agricultura familiar en Brasil. Revista CEPAL, 111, 103-121.

Walsh, C. (2010). Monetary Theory and Policy (3nd ed.). Cambridge: The MIT Press.

Ward, J. H. (1963). Hierarchical grouping to optimize an objective function. Journal of the American Statistical Association, 58, 236-244. 